\title{
DIALÉTICA, MARXISMO MULTIDISCIPLINAR E CORPOREIDADE
}

\author{
Enéas Arrais Neto ${ }^{1}$
}

\begin{abstract}
Resumo
Este texto ensaístico apresenta as primeiras aproximações de uma reflexão que pretende rearticular elementos chave metodológico da perspectiva tradicional da Dialética Marxista. Parte-se da compreensão de que o enfoque tradicional vigente da concepção metodológica e epistemológica da Dialética expressa uma matiz racionalista com forte base objetivista, representada pela prioridade dada à Economia Política Crítica, como elemento central da análise social. Resumidamente, esse enfoque tradicional refere à Ação Social ou a Ação Pessoal dos sujeitos sociais a seus conteúdos de classe ou a referências históricas racionalmente definidas, desconsiderando aspectos claramente verificáveis, e que se faz necessário considerar da ordem dos afetos, da emoção e de outros campos normalmente referidos ao inconsciente. A teleologia da ação humana se configuraria, dessa forma, no campo definido pela racionalidade social ou razão pessoal articulada a partir do histórico-social, excluindo fatores pessoais tidos como irracionaisque efetivamente definem aspectos centrais da ação social e política dos sujeitos históricos. Metodologicamente, o artigo se conforma como estudo teórico bibliográfico, cotejando obras de vários autores no sentido de vislumbrar a unidade possível entre elementos comumente tidos como opostos ou como contraditórios, se enfocados a partir da lógica não totalizadora da ação humana. Desenvolve-se a ideia de que a Dialética tradicional com toda a riqueza metodológica que representa, e consideradas suas contribuições interdisciplinares está limitada à perspectiva da consciência entendida como racionalidade consciente, considerando os aportes da psicanálise e da fenomenologia de Merleau-Ponty que podem representar contribuições inovadoras e enriquecedoras à Dialética, em seu caráter de Metodologia, teoria epistemológica e gnosiológica, pela consideração do 'Inconsciente' e da 'Intuição Selvagem', sugeridos pela psicanálise e pelos estudos de Merleau-Ponty.
\end{abstract}

Palavras-chave: Dialética. Epistemologia. Gnosiologia. Teoria-Crítica.Fenomenologia.

\begin{abstract}
This essay develops a critique of the traditional perspective of Dialectics. Departing from the general caracteristics of dialectics, commonly assumed by Marxist scholars, subsumed in the area of rationality, it presents the author's version of an enriched and enlarged perspective of an epistemologic theory. In this enlarged and 'transdiciplinary' mode, it is considered that we could assemble the achievements of the 'classical' dialectics and the contributions of the theories of 'psique' brought through the Critical Theory of 'The Frankfurt School' and the Phenomenology of Merleau-Ponty, putting together contributions of the studies of uncountiousness and intuition. Although generally considered contradictory, these diverse methodological approaches can, if fact, enrich and enlarge one another by self nourishment.
\end{abstract}

Keywords: Dialectics. Epistemology. Critical Theory.Phenomenology.

\section{1) Elementos Característicos da Dialética}

Dialética é um termo semanticamente plural. Significa de forma geral desde a essência dialógica ou dialogal do desenvolvimento de um debate, com a articulação de ideias contraditórias, passando por questões ligadas ao desenvolvimento de uma ontologia não metafísica que incorpora a transformação e o movimento como aspectos essenciais da realidade, concebendo essa realidade como unidade de elementos contraditórios, e chegando a temáticas mais específicas desenvolvidas no campo do marxismo. Neste, encampa aspectos

\footnotetext{
${ }^{1}$ Professor, Doutordo Programa de Pós-Graduação em Educação Brasileira da Universidade Federal do Ceará. (FACED/ UFC).
} 
fundamentais referidos à ontologia (dialética como caráter dinâmico, complexo e conflituoso da realidade social, que incorpora aporias e oposições articuladas em unidades contraditórias). Por outro lado, o termo dialética,refere-se aos elementos centrais do marxismo como metodologia-teoria da ciência ou do conhecimento, isto é: epistemologia e gnosiologia, articulados ou não com seu aspecto de Teoria da Práxis - teoria da ação social.

A reflexão sobre Dialética proposta neste texto se desenvolverá a partir de sua perspectiva de corrente gnosiológica e metodológico-epistemológica, articulada com sua propositura enquanto Teoria da Práxis, norteadora da ação humana crítica, práxis social de sujeitos que tomam nas mãos as rédeas de sua história, inserindo-a inextrincavelmente na história mais geral coletiva, regional, nacional e universal. Conforma, desta maneira, um conjunto compreensivo de ser-pensar(se)-agir situado historicamente e que busca dar conta do real considerando seu caráter dinâmico, transitório, plural, contraditório, e complexo nesta pluralidade conflituosa que conforma uma unidade social a cada momento e em contextos geopolíticos específicos. Para além dessa perspectiva mais comumente aceita, acrescentaremos nesta exposição, de forma concatenada, as contribuições trazidas pelo aporte psicanalítico da Teoria Crítica e pela perspectiva fenomenológica de Merleau-Ponty. Estas contribuições, enfocadas a partir de uma perspectiva de complementaridade e não de oposição, permite, a nosso ver, a incorporação de elementos de compreensão do agir humano para além da racionalidade instrumental e do racionalismo como paradigma referencial de ação. Apontam para a apreensão intuitivo-corporal do mundo e para a ação-reação emocional irracional, baseada nos condicionamentos inconscientes. Pretendemos fazer, assim, uma atualização que nos parece além de interessante, necessária à dialética, como possibilidade analítica da ação humana que efetivamente não é apenas racional, mas rica de contradições em relação às motivações declaradas.

\section{1) Dialética e Dialéticas}

Quando nos referimos acima à Dialética como conjunto articulado, não queremos significar que suas várias correntes e perspectivas são organicamente ou sistematicamente coerentes ou que constituam uma tessitura linear ou acumulativa. É razoavelmente tranquilo para qualquer observador sincero notar que entre as várias vertentes que se ab-rogam o epíteto de dialéticas reina, mais das vezes, oposição, contradições, conflitos e enfrentamentos, em que cada posição presume a posse da verdade, ou, em alguns casos (é forçoso reconhecer que poucos), estabelecem complementação e enriquecimento mútuo. Os entraves e disputas

\begin{tabular}{|l|l|l|l|l|}
\hline Q Rovista Dialectus & Ano 2 & n. 6 & Janeiro - Agosto 2015 & p. 177-191 \\
\hline
\end{tabular}


políticas, de poder, de comando ou de sucesso social, seja no âmbito partidário ou no das disputas interpessoais se apresentam sempre como o obstáculo nunca reconhecido no discurso 'oficial' de uma teoria que advoga a racionalidade como eixo motivador da ação humana.

Talvez, a entronização do Marxismo Soviético como critério de verdade teóricoprático e metodológico, a partir do estabelecimento da primeira revolução vitoriosa sob o manto do Socialismo Científico seja o fato explicativo ou deflagrador dessa compreensão errônea e limitada da práxis (vitória política efetiva) como critério de verdade. Baseada em uma leitura descontextualizada da expressão aludida por Marx nas teses contra Feuerbach (a práxis é o critério da verdade histórica), essa concepção hipostasiou a posição política de apoio e adesão à Revolução Soviética como fonte da verdade "revolucionária". Abriu-se espaço, a partir desse contexto histórico de combates, para a consolidação absolutista de concepções particulares instauradas no poder "soviético", das quais decorreu a presunção, ou determinação de posse de uma verdade excludente.

Como consequência dessa tautologia pode-se autoproclamar a verdade, elaborando uma ortodoxia interpretativa que ditatorialmente passou a definir o pensamento 179 divergente como contra-revolucionário, burguês ou equivocado de nascença, por heterodoxia. Cabe perceber que este tipo de posicionamento, geralmente atribuído ao estalinismo, expandiu-se genericamente numa postura comum para um amplo espectro das correntes políticas e acadêmicas do marxismo (a perspectiva acadêmica não acontece num campo neutro, desvinculado de interesses políticos e partidários, nem mesmo de interesses e disputas pessoais).

Isto posto, é forçoso aceitar que o desenvolvimento mesmo de uma tal perspectiva "crítica desinteressada", como a que advogamos, deve ser entendido e situado num campo de "interesse" que não deixa de ser também político. O suposto "desinteresse" partidário ou sectário que assumimos e buscamos conscientemente é filho de posições políticas que não encontraram nos partidos e correntes existentes sua expressão adequada ou neles não se reconheceram. Não se pode presumir uma posição purista. Cabe-nos sempre a autoanálise inicial e a explicitação do reconhecimento de nossa própria perspectiva como situação específica. Nisso, cremos, está a clareza necessária e a forçosa 'humildade' de qualquer pesquisador.

\section{2)Aspectos de unidade na Dialética}

\begin{tabular}{|l|l|l|l|l|}
\hline Q Ronista Dialectus & Ano 2 & n. 6 & Janeiro - Agosto 2015 & p. 177-191 \\
\hline
\end{tabular}


Por outro lado, quando dizemos da dialética como conjunto articulado, queremos significar que para um sujeito que exercite a ação de pensador não somente crítico, como autocrítico, e busque a construção de um saber que lhe norteie a práxis, considerando a ação humana em toda sua complexidade, contradições, movimento e unidade, é possível conjugar consistentemente o aporte de várias correntes que se aproximam ou que digladiam em busca da "liderança" no movimento político ou acadêmico do marxismo. Conhecimento é sempre e apenas uma "aproximação do real”, com limitações de aceitação necessária.A realidade é inesgotável em sua complexidade que reconhecemos irredutível ao conhecimento. O saber humano, na perspectiva dialética nunca é definitivo ou completo, tendo na parcialidade, contexto e temporalidade elementos de limitação definitivos.

Desta forma, este saber, mesmo que dialeticamente considere pluralidade, complexidade e contradição, é sempre e apenas uma aproximação da verdade, aquela verdade que seria explicação completa ou definitiva dos processos sociais. Conquanto permita o desvelamento da estrutura da ação social-histórica em termos de concepção geral dos elementos constitutivos do processo histórico analisado, nunca atinge o esgotamento de todos os aspectos possíveis que efetivamente intervieram em sua realização. Compreendemos dialeticamente que é possível entender aproximadamente os processos e fatos históricos porque eles são construídos pelos seres humanos, dentro de contextos que os condicionam e a partir dos quais buscam imprimir seus interesses, sejam pessoais ou coletivos. $\mathrm{O}$ conhecimento é, então, a busca, a partir de determinadas perspectivas, de explicitação dessas estruturas da ação humana que cria a história e seus fatos.

Tomando esses dados, e reconhecendo que não é pequeno e não se assume como simplório o salto que será proposto a seguir, cabe reconhecer que partimos todos de uma base comum neste vasto campo abrangido pela identificação de Dialética. Elemento fundamental, como se configura a compreensão da irredutibilidade do ser (realidade histórica) ao pensar (teoria), se mostra como característica de humildade essencial de uma metodologia que percebe que o conhecimento não esgota o real. A verdade definitiva ou completa é inacessível por não termos conhecimento exaustivo de todos os elementos da ação humana e de suas relações em meio a estruturas postas que a configuram como fato histórico.

A aceitação desta premissa, entretanto, não desfaz a possibilidade de desvendamento aproximativo do conhecimento, quando elabora mentalmente a reestruturação sintética da "teia" entrecruzada da ação humana constituinte de um processo histórico. Busca-

\begin{tabular}{|l|l|l|l|l|}
\hline Genista Oialectus & Ano 2 & n. 6 & Janeiro - Agosto 2015 & p. 177-191 \\
\hline
\end{tabular}


se a verdade como um caminho brumoso no qual dispomos de bússola, o que não nos impede o evento de quedas, tropeços e desvios.

Tomaremos igualmente como posto e aceito por todas as correntes o caráter dinâmico da realidade, aspecto central do pensamento dialético desde Heráclito, na Grécia antiga. O movimento, implicando em mudança e transformação, é expressão de uma pluralidade articulada em totalidades que incluem em unidades (o todo) os elementos contraditórios e conflituosos, estabelecendo um movimento complexo não caótico, embora igualmente não orgânico dos processos históricos ${ }^{2}$. Poderíamos chama-lo de movimento conexo na totalidade.

É interessante, acrescente-se, analisar a forma complexa, interdisciplinar, assumida pelas análises elaboradas pelo próprio Marx, mormente em suas obras posteriores ao acerto de contas com o hegelianismo. Essa Interdisciplinaridade que estrutura um conhecimento unitário complexo da realidade, incomum ainda hoje e seminal em seu tempo, é um aspecto que causa incompreensão de sua obra, de sua perspectiva mesmo, levando a oposição por parte de intelectuais conservadores.

É neste sentido que se pode compreender a objeção que as várias áreas de conhecimento especializado expressam acerca da obra do "velho diabo"3, negando-lhe o direito de ser tido como "economista" pelos economistas, reconhecimento igualmente negado pelos "filósofos" e "sociólogos" de matiz corporativista, e que encontra respaldo em vários outros campos profissionais. É característica estruturante dessa "profissionalização" do fazer e do pensar, o fato de que observem o mundo a partir de seu viés particular e especializado, inclusive na utilização de linguajar e jargão próprios. Marx é um economista ou sociólogo, dizem os que observam o mundo a partir da filosofia "pura"; é um filósofo ou político, dizem os economistas de formação clássica; é economista ou filósofo, dizem os sociólogos de matiz positivista ou funcionalista.

Poderíamos dizer que estão todos certos, e, a partir dessa mesma constatação, estão todos errados. A superação da suposta antinomia está na perspectiva não apenas multidisciplinar, mas transdisciplinar que assume a análise de Marx acerca dos fenômenos históricos, articulando áreas diversas do conhecimento e entrecruzando enfoques

\footnotetext{
${ }^{2}$ A obra de KarelKosic: A Dialética do Concreto (1985) é, neste sentido, uma excelente referência, além de, provavelmente a mais utilizada e aceita acerca da explicitação da construção dialética do conhecimento.

3 “Old Nick”, alcunha amistosa com que o 'velho’ Marx era chamado pelos companheiros políticos.
}

\begin{tabular}{|l|l|l|l|l|}
\hline Revista Dialectus & Ano 2 & n. 6 & Janeiro - Agosto 2015 & p. 177-191 \\
\hline
\end{tabular}


complementares em unidades sintéticas complexas que incorporam compreensão da economia, das relações sociais, de processos históricos, pensados como totalidades unitárias compreendidas e expressas a partir de categorias filosoficamente articuladas. Explicitamente, sua análise combatia o enfoque especializado parcial, considerado por Marx "a origem dos equívocos" no conhecimento social.

Entretanto, essa característica necessariamente plural, complexa e multidisciplinar do pensamento expresso na obra de um pensador prodigioso foi reduzida, por vezes, à simplificação da estruturação de forças econômicas que seriam os determinantes finais da realidade. Linearmente, se concebeu determinações da base econômica sobre as superestruturas jurídico-políticas e ideológicas como o vetor fundamental de explicação da sociedade, restando a "ação de retorno" como aspecto de menor impacto histórico de influência das superestruturas sobre a base produtiva. As perspectivas reducionistas (objetivistas, racionalistas, economicistas, positivistas) de algumas correntes do marxismo compreendem que o todo (economia-sistema capitalista ou socialista) determinaria-explicaria as partes (elementos da superestrutura).

Regredindo a uma forma de racionalismo teórico, a economia política crítica foi transformada numa teoria da permanente crise do capital que tudo explicaria, por significar a expressão de uma essência da sociedade atual, cujas manifestações singulares, parcelares ou de qualquer outro tipo, seriam apenas variações fenomênicas de menor importância. A história real, constituída pela ação humana e suas motivações pessoais, inserida em relações sociais de produção, ficaria subsumida a determinações da economia sobre o mundo da cultura e sobre as relações e estruturas políticas, pressupondo uma objetividade das estruturas sociais que submeteria completamente a subjetividade humana numa linearidade de condicionamento unidirecional.

Esse aspecto particular da influência da subjetividade e da própria compreensão de como se constitui essa subjetividade é o foco do que aqui queremos desenvolver como elemento de síntese da Dialética clássica (Marx, Lukacs, Kosic), das contribuições da perspectiva psicanalítica, sugeridas pelo marxismo interdisciplinar do grupo nucleado teoricamente em Frankfurt (Marcuse, Adorno, Bloch, Fromm), e da perspectiva gnosiológica da Fenomenologia marxista de Merleau-Ponty (particularmente, seu pensamento acerca da corporalidade-corporeidade de nossa relação com o mundo vivido).

\begin{tabular}{|l|l|l|l|l|}
\hline Qevista Dialectus & Ano 2 & n. 6 & Janeiro - Agosto 2015 & p. 177-191 \\
\hline
\end{tabular}




\section{2) A relação Sujeito-Objeto e a Dialética no processo do conhecimento}

A Filosofia da Ciência tem o tema da relação entre sujeito e objeto como elemento central na definição das teorias do conhecimento. Todas as questões de método decorrem do estabelecimento inicial da compreensão desta relação, tradicionalmente, com a definição de qual desses elementos é o centro do processo. Efetivamente, quando dizemos que há conhecimento, expressamos que alguém (sujeito) conhece algo (objeto, parte ou todo da realidade).

Ao longo da história da filosofia e da ciência, as várias correntes partiram de um polo ou outro (sujeito e objeto) como definidor da construção do saber, elegendo os processos de indução ou dedução como ponto de partida gnosiológico e epistemológico. Privilegiou-se ora o racionalismo, ora o empirismo, como meio de investigação e construção científica e filosófica, conferindo maior ênfase a posturas idealistas ou realistas, todas conforme o polo primaz escolhido. Construiu-se, desta forma, reconhecidas as grandes contribuições à Filosofia e à Ciência aportadas por várias dessas correntes, metodologias de conhecimentosempre dicotômicas e parciais pela negação ou redução do polo desvalorizado. A filosofia e a ciência são, tradicionalmente, ou objetivistas(objetivismo, realismo, empirismo, indutivismo) ou subjetivistas (subjetivismo, idealismo, racionalismo, dedutivismo), privilegiando umas o elemento da Prática da Pesquisa, outras o aspecto da Teoria.

Considerando esse ponto como dado inicial, debate posto e já muito explorado, partiremos da postulação de que a Dialética seria uma metodologia que superaria essa dicotomia por incorporação dos dois polos em uma unidade relacional. Para a Dialética, Sujeito e Objeto somente existem interligados e inter-relacionados no processo do conhecimento. O conhecimento se inicia pelo estabelecimento da relação mesma entre esses polos, relação que é algo vital.Vida em que o ser humano se confronta-encontra e relaciona com os outros e com o mundo objetivo de coisas, estruturas, instituições, ideias. Sujeito e Objeto gnosiológicos, filosóficos e científicos, inclusive se constituem, em suas identidades, neste processo mesmo, somente existindo nesta relação mutua em que um ser humanopensador-pesquisador define um objeto de interesse que, existindo por si, independente do conhecimento humano, se torna, a partir dessa escolha OBJETO no sentido do conhecimento. Essa escolha-atividade de conhecer algo, por sua vez é que caracteriza o ser humano referido

\begin{tabular}{|l|l|l|l|l|}
\hline Q Povista Dialectus & Ano 2 & n. 6 & Janeiro - Agosto 2015 & p. 177-191 \\
\hline
\end{tabular}


como SUJEITO de conhecimento, tanto no sentido geral quanto nos sentidos filosófico e científico.

A questão central que nos interessa é que as vertentes iniciais da dialética desenvolvida pelo Materialismo Histórico a partir de Marx, e filosoficamente encorpada e analiticamente desenvolvida pelas contribuições de Georg Lukacs e KarelKosic, se contém ou privilegia o enfoque da ação humana como ação racional. A relação de conhecimento do mundo, tendo no Trabalho sua atividade de base, ontologicamente constituidora do Ser Social,considera a ação humana como teleologicamente motivada pela racionalidade dos objetivos explícitos (conscientemente) da intervenção do ser humano, tanto no que se refere ao mundo dos objetos quanto ao mundo dos seus semelhantes e das relações sociais.A ação humana teria sua teleologia (interesses e intenções contidas no 'projeto da ação') definida a partir da motivação de fins racionais, dos quais o ser humano é consciente. Há algo que eu digo que quero ou explicitamente penso que quero, justifico que quero, e essa declaração da razão seria o que moveria a ação, a práxis humana. Mesmo a emergência do estranhamento, como processo posterior de não reconhecimento de si no produto da ação (produtiva ou social), não invalida, nesta perspectiva,o caráter de intencionalidade racional do fazer humano.

Estaríamos, ademais, todos nós, histórica e socialmente situados como sujeitos dessa ação, o que seria seu aspecto fundamental de condicionamento ${ }^{4}$. Pertencemos a uma Classe, estruturada a partir das relações de trabalho e produção, que seria a categoria mais profundamente definidora de nossa práxis social histórica. Não pensamos ou nos situamos como indivíduos isolados.A Dialética reconhece, já com reflexo de influências anteriores a Marx, que pensamos, e consequentemente, agimos, a partir dos contextos estabelecidos pelos grupos sociais aos quais pertencemos. Estes, por sua vez, refletem condicionamentos sóciohistóricos de suas épocas e 'lugares'. No entanto, a Classe Social, como grupo definidor fundamental de nossa ação, mesmo sendo algo difuso, grupo ao qual se pertenceria primariamente de forma objetiva (relação em-si) e só secundariamente se constituiria a pertença consciente (relação para-si), seria a coletividade central no condicionamento da ação humana histórica.

${ }^{4}$ Para já não utilizarmos o termo 'determinação', claramente mais mecanicista.

\begin{tabular}{|l|l|l|l|l|}
\hline Gonista Dialectus & Ano 2 & n. 6 & Janeiro - Agosto 2015 & p. 177-191 \\
\hline
\end{tabular}


O processo de trabalho é definido como a ação humana paradigmática, além de constituidora ontológica do ser humano como Ser Social. Esse processo ontologicamente paradigmático é muitas vezes compreendido como uma essência última inextrincável que se manifestaria em todo e qualquer ato humano. A forma do processo de trabalho humano, como ação transformadora da realidade natural, pela rearticulação de seus condicionantes objetivos, postos pela natureza (o objeto natural conforme suas características próprias), acontece pela imposição da teleologia subjetiva (projeto consciente) do ser trabalhador sobre essa determinação original. Atinge-se, pela interposição do projeto subjetivo consciente, a transformação do objeto natural, com suas características objetivas, em objeto social, cultural, histórico, humano, que passa a ser, a partir dessa nova pertença, um novo tipo de objetividade condicionante da história (causalidade posta). Resumidamente, o ser humano constrói o mundo histórico por sua ação social, que é ação intencional (subjetividade que estabelece projetos transformadores - teleologia) sobre elementos da natureza, com suas características próprias e reais (objetividade, causalidade), transformando-a em mundo humano, social, cultural (causalidade posta) que também tem características próprias objetivas. Neste procedimento, ele estabelece relações com outros seres humanos, com interesses e intenções (teleologia secundária) que são também definidos conscientemente e racionalmente (mesmo que 'maculados' pelo estranhamento e alienação).

Todo esse complexo tecido de ações sociais individuais e coletivas, tem na consciência e na razão seu elemento de intenção motivadora. Na leitura tradicional do Materialismo Histórico, principalmente em se tratando de ação política ou histórica coletiva, a racionalidade classista é o referencial que motivaria e explicaria a intencionalidade dos sujeitos históricos. A única opção possível, no quadro da racionalidade é a consciência e a razão distorcidas pela ignorância, reflexo da mistificação da realidade pela ideologia como fenômeno parcial e igualmente classista.

\section{3) $O$ inconsciente e o corpo como elementos condicionantes da ação}

Marx é um pensador que elabora sua produção ao longo de quatro décadas intermediárias do século XIX. Não teve, por seu próprio enquadramento histórico, contato com o desenvolvimento de estudos da psicanálise e da psicologia estabelecidos majoritariamente a partir das primeiras décadas do século XX e, a partir daí, grandemente desenvolvidos como campo específico do saber com influências basilares sobre a compreensão do agir humano.Contanto, se não se pode esperar a presença de estudos ou do

\begin{tabular}{|l|l|l|l|l|}
\hline Q Rovista Dialectus & Ano 2 & n. 6 & Janeiro - Agosto 2015 & p. 177-191 \\
\hline
\end{tabular}


conhecimento da psicologia sobre a obra basilar de Marx, o mesmo não se aplica aos pensadores marxistas da atualidade ou mesmo aos grandes epígonos do marxismo do século XX.

Tendo convivido com os estudos da Psique, seja sob o enfoque da psicanálise ou como diversas correntes da psicologia, o caudal predominante do marxismo e da dialética, representado na corrente do marxismo político e da economia política crítica como referências teóricas de leitura da realidade social, desconheceu, negou ou não incorporou as contribuições dessa área á compreensão da ação humana. Quando dizemos caudal, nos referimos à existência de várias correntes, cuja divergência em questões outras (políticas, teóricas etc.), as leva no mesmo sentido quando se baseiam na consciência e na racionalidade em relação aos fins e meios como aspectos fundantes inarredáveis da ação humana social.

Mesmo reconhecendo a existência dos estudos do grupo composto por Vigotsky, Leontiev, Luria, e que também Gramsci tangencia questões da psique, para as correntes predominantes tradicionais do Marxismo, a Dialética abrangeria a complexidade, contradição e unidade do real engendrado pela ação humana, na medida em que se concebe que esta ação tem como referenciais formas de teleologia racionais. Os sujeitos sociais sejam através da ação classista coletiva ou em sua ação individual (como membro de uma classe, conscientemente ou alienadamente) frente à história, seja nas ações pessoais do cotidiano, seriam motivados por opções, decisões e projetos sempre referidos a intenções racionalmente definidas. Mesmo quando a ação se limita à contingência do âmbito individual-pessoal, ela seria motivada por padrões de ação pessoal burguesa ou proletária, como reflexo da ideologia (cultura) alienada ou consciente, em termos do referencial de classe.

O enriquecimento dessaperspectiva de análise com a incorporação de novos referenciais tem seu momento demarcatório estabelecido pela emergência do Marxismo Multidisciplinar da Escola de Frankfurt e de autores que em torno dela desenvolveram sua produção teórica. O marxismo anterior ao grupo de Frankfurt teve nos partidos comunistas seu repositório da ortodoxia, o que era natural em certo sentido, posto que, surgido do movimento operário e político partidário, e nele tendo seu campo de atuação essencial, foi na expressão partidária do comunismo e no sindicato vinculado ao partido que permaneceu o estudo e difusão da análise dialética de Marx e de sua teoria política. A tomada do poder na União Soviética transportou a concepção de marxismo, de dialética e de materialismo

\begin{tabular}{|l|l|l|l|l|}
\hline Q & Donista \\
\hline
\end{tabular}


histórico prevalecente no partido comunista para a academia russa, oficializando uma concepção parcial como posição e interpretação definitivas.

As divergências políticas, tornadas ou compreendidas como diferenças de interpretação deram vazão a disputas em que acusações de desvio e revisionismo foram a pecha atribuída aos grupos minoritários discordantes da doxa (opinião) majoritária ou do grupo dirigente. Esse procedimento contribuiu para a manutenção de um Marxismo oficial, de cuja ortodoxia (orto-correta doxa-opinião) se incumbia a cúpula de comando do partido, e que era difundido como metodologia de análise oficial dos sindicatos filiados à corrente comunista.

A vitória do partido comunista à frente da Revolução Soviética Russa como expressão de um primeiro momento que, na concepção progressista linear, se desdobraria em uma revolução mundial, levou ao movimento decorrente de fortalecimento e de entronização do Marxismo Soviético do PCUS como referência oficial do que seria definido como Marxismo ou Dialética.Doravante a definição de interpretação verdadeira ou errônea do marxismo e a determinação de quem seria revolucionário ou reacionário assumia uma referência oficial no partido comunista dos vários países, cujas células nacionais eram referendadas por seguir a liderança da 'Pátria Mãe do Socialismo', representada pelo PCUS. Associado às análises histórico-políticas de Lênin, a teoria tornou-se Marxismo-Leninismo, como teoria da ação histórica revolucionária. Todo esse desenrolar, promoveu-se dentro do enquadramento da razão eficiente ou do agir racional com respeito aos fins, como elemento de motivação teleológica do ser humano.

O Marxismo Multidisciplinar iniciado na Escola de Frankfurt e desenvolvido por pensadores que conviviam em meios intelectuais (Lukacs seria provavelmente uma das maiores referências desse grupo corolário) é um marxismo de caráter acadêmico. Diferente do marxismo político dos partidos comunistas e de sua politicamente justificada unidade, o marxismo nascido dos intelectuais acadêmicos é marcado quase que necessariamente pelo signo da pluralidade de ideias, da discordância possível, das temáticas diversas desenvolvidas a partir de campos do conhecimento universitário ou intelectual de grande tradição, levando ao entrecruzamento de perspectivas e a um decorrente enriquecimento dos referenciais teóricos.Temas como Estética, Teoria da Literatura e da Arte, Teorias da Psique, Psicanálise, e leituras sociológicas, históricas e filosóficas de matiz universitário, foram o eixo de desenvolvimento teórico do pensamento de autores que eram acadêmicos ou que com eles

\begin{tabular}{|l|l|l|l|l|}
\hline Qevista Qialectus & Ano 2 & n. 6 & Janeiro - Agosto 2015 & p. 177-191 \\
\hline
\end{tabular}


conviviam ou dialogavam. O debate e o encontro dessas formas diversas de desenvolver o pensamento dialético enriqueceram as perspectivas desses vários teóricos, trazendo, em particular, a contribuição das diversas vertentes de estudos da psique humana aos objetos de estudos variados, à compreensão da ação humana emocional e irracional, aos limites da racionalidade e, dessa forma, à dialética como teoria do conhecimento e da ciência.

Iniciados como Psicanálise, mas com contribuições que variaram de conflitivas a complementares, as concepções de Inconsciente e pulsões (Freud, Jung, Lacan), Sonho Diurno e Esperança Douta (Ernst Bloch), Erotismo, Sociedade, Desejo e Prazer (Freud, Marcuse), Sociologia como Psicanálise Social (Erich Fromm, Marcuse), os aportes desses e de outros pensadores apontaram para motivações da ação humana individual e social a partir de novos paradigmas não racionais (inconsciente, irracional, pulsões, desejos, libido, sonhos, traumas, neuroses).Independente das contribuições particulares decorrentes da aplicação dessas teorias aos objetos de estudo específicos determinados pelos interesses pessoais dos intelectuais em questão, ou, explicando de outra forma: apesar de que os temas objeto de seus estudos não sejam organicamente articulados numa unidade ou continuidade estruturada num todo sistemático e internamente coerente, o aspecto mais importante que emerge coletivamente de sua contribuição é uma teoria dos elementos não racionalizáveis da ação humana.

Seja permitindo descobrirmos elementos do inconsciente como "lugar das pulsões reprimidas na infância", seja contrapondo o Sonho Diurno ou a Esperança Fundada, como direcionamento consciente dos desejos e anseios coletivos nascidos de projeções das carências humanas, seja contrapondo a construção da estrutura social como interposição do projeto cultural humano sobre as pulsões eróticas e sensuais dos instintos individuais, ou outros elementos singularmente desenvolvidos pelos estudos dos teóricos que gravitaram em torno da Escola de Frankfurt, o que nos chama a atenção é a unidade, mesmo nebulosa, da justificação não simplesmente racional do agir humano.A adição permitida pela percepção desses elementos permite que compreendamos os processos históricos de disputa, competição, expurgos, perseguições e outros, acontecidos entre personagens e correntes das lutas dos setores subalternos, que aparece nas diversas leituras históricas como 'loucura', 'desvios' ou 'traição à causa'. A suposta coincidência de interesses na revolução não foi suficiente para que o trato entre os vários grupos e correntes marxistas fosse diferenciado daquele

\begin{tabular}{|c|c|c|c|c|}
\hline Q Rovista Dialectus & Ano 2 & n. 6 & Janeiro - Agosto 2015 & p. 177-191 \\
\hline
\end{tabular}


direcionado à reação social e política burguesa, fazendo emergir disputas sangrentas e por vezes desumanas pelo poder e prestígio sociais.

Parece-nos que se estabelece com razoável clareza que a análise histórica com o mínimo necessário de afastamento denuncia motivações pessoais de cunho inconfessável ou inconsciente, baseados em elementos de disputa, imagens de sucesso e liderança, ocupação de papéis centrais na sociedade, no partido e na história oficial, afetos e emoções decorrentes dessas bases, como elementos definidores de ações e processos políticos ainda hoje dolorosos na consciência, inexplicáveis sob o paradigma da racionalidade Greco-ocidental. O apelo à constituição de ídolos e de monstros explicativos desses processos históricos (Stalin é sempre um bom exemplo de como se podem assumir ambos os papéis, deacordo com a circunstância da análise e o interesse político em voga) apenas reflete as tentativas de racionalização de motivações que serão sempre racionalizáveis 'a posteriori' ou racionalizáveis como parte de um discurso político monolítico e de poder.

Percebemos que muito ainda se deverá andar por essa senda, no sentido de tornarmos mais densas e encorpadas essas observações reconhecidamente perfunctórias. 189 Apontamos justamente para a perspectiva de desenvolvimento desse veio riquíssimo aportado pelos estudos psicanalíticos e psicológicos como um aspecto novo de imenso poder de impacto sobre a análise histórica e sobre a Dialética como metodologia-epistemologiagnosiologia complexa e incorporadora dos aspectos contraditórios do ser humano e de sua ação.Esse rápido apontar de algumas questões referidas à psique não esgota, mesmo sob esse aspecto as contribuições de Marcuse, Bloch, Sartre, Gramsci e vários outros autores que, no campo do marxismo, materialismo histórico ou dialética, apresentaram em seu pensamento elementos dessa reflexão sobre a subjetividade, tanto consciente como não consciente. Neste sentido, é obrigatório ainda reconhecer que análises sociais como a de Marcuse, de Ernst Bloch e Erich Fromm, aplicam essa perspectiva dos estudos da psique à história e à ação social para além do indivíduo e de sua ação pessoal. Todo este campo nos parece ainda por expandir e melhor explorar.

Por outro lado, o exercício do pensar dialético de Maurice Merleau-Ponty, incorporando a perspectiva fenomenológica sob um enfoque crítico não restritivo nos aparece como uma contribuição ainda não devidamente ponderada e riquíssima, que pode ampliar o escopo compreensivo da Dialética como teoria do conhecimento e metodologia científica, bem como do Materialismo Histórico como teoria da ação histórica e social.

\begin{tabular}{|l|l|l|l|l|}
\hline Gevista Dialectus & Ano 2 & n. 6 & Janeiro - Agosto 2015 & p. 177-191 \\
\hline
\end{tabular}


Tendo partido de um duplo veio do marxismo ocidental ${ }^{5}$ e da fenomenologia de Husserl e Heidegger, Merleau-Ponty elabora uma perspectiva da fenomenologia como gnosiologia que a nosso ver enriquece sensivelmente as possibilidades compreensivas da dialética, num sentido paralelo aos estudos da psique. Se opondo ao conceito de inconsciente psicanalítico, que criticava por situar o motor da ação num 'lugar' das pulsões e desejos reprimidos, lugar psíquico de onde as "feridas da alma" passam a dirigir a ação pessoal de forma e sentidos grandemente encobertos ao próprio sujeito,Merleau-Ponty pensa sua fenomenologia a partir da ideia de corporeidade. O ser-no-mundo fenomenológico é, para ele, um ser essencialmente corpóreo (incorporado, corporificado). Nossa relação com o mundo, antes de ser racionalizada é uma relação não analítica, não fragmentada, de sensos (sentidos corporais) integralizados em experiências que constroem uma percepção sintética que ele chama de 'intuitiva selvagem'. O Intuitivo merleau-pontiano não tem a ver com algo incompreensível ou exotérico. Intuitiva é a apreensão global totalizante que fazemos inicialmente, anterior às racionalizações, fragmentações analíticas, teorizações e explicações que damos de nossas experiências.A partir dessa proposição, aquilo que na psicanálise é atribuído ao inconsciente, Merleau-Ponty o refere ao hábito incorporado. O Corpo se habitua a agir de certa forma em resposta aos estímulos externos mediados pela intuição selvagem. Hábito que reflete, inclusive, a incorporação de reações desequilibradas, emocionalmente imaturas que a psicanálise atribui ao inconsciente e que em sua leitura (Merleau-Ponty) são manifestações de uma atitude cristalizada com entraves.

De uma forma geral e numa aproximação primária, a contribuição central de Merleau-Ponty é a possibilidade de pensarmos que nosso estar no mundo, incluindo nossa ação, não é norteado por nossa racionalidade explícita, pela razão declarada. Não somos seres agindo a partir de nossos intelectos racionais. Somos seres humanos integrais e indivisíveis, e nossa integridade não pode ser resumida ao intelecto ou à razão. Nossa pertença ao mundo é integral corporificada, somos intelectos articulados a emoções e afetos apreendendo um mundo que nos chega através dos sentidos corporais sem decomposição analítica ou teórica. Primeiramente vivemos o mundo e o sentimos (inclusive num sentido afetivo e emocional gostar, desgostar etc.), e somente depois, secundariamente, o pensamos e teorizamos com o pensamento analítico racional. Nossas racionalizações, inclusive, expressam muito de nossos

\footnotetext{
${ }^{5}$ A expressão Marxismo Ocidental se refere ao marxismo produzido por um grupo de pensadores independentes, desvinculados do comando do PCUS. No caso de Merleau-Ponty, a influência maior, neste sentido é do húngaro Georg Lukacs e seu livro História e Consciência de Classe.
}

\begin{tabular}{|l|l|l|l|l|}
\hline Govista Dialectus & Ano 2 & n. 6 & Janeiro - Agosto 2015 & p. 177-191 \\
\hline
\end{tabular}


quereres radicados na apreensão intuitiva inicial. Racionalizamos e explicamos o que gostamos a partir de elementos diferentes de como racionalizamos e explicamos o que não gostamos. É necessário reconhecer que nunca poderemos ser neutros por princípio.

Esse nosso estar no mundo torna 'naturais' certas perspectivas, a partir da sedimentação histórica de nossos afetos e emoções, o que nos deve levar ao esforço de sempre buscar desenvolver algum nível de "estranhamento" frente à realidade, buscando fugir do costume de nossa própria postura prévia e do olhar 'normal' dela decorrente. Esse estar no mundo a partir dessa intuição 'selvagem' é reconhecidamente, também, inserido em contextos sociais e pessoais que se torna necessário reconhecer. Os grupos dos quais fazemos parte, nossas pertenças afetivas, emocionais, culturais e, mesmo, intelectuais (que passam a articular nossa afetividade e emoção, em retorno), são elementos definidores das racionalizações que intentam a explicação intelectualizada e 'científica' da realidade.

Há uma grande possibilidade de enriquecimento e complexidade a serem incorporadas à dialética, como gnosiologia, epistemologia e teoria da ação social, a partir do pensamento de Merleau-Ponty, principalmente no que diz respeito a sua Teoria da Percepção, 191 o que, nos parece, abre novas e vastas sendas a serem percorridas por todos que se reclamam herdeiros sinceros do pensamento crítico na tradição do Materialismo Histórico.

\section{Referências}

ADORNO, Theodor. Dialética negativa. Rio de Janeiro, Zahar, 2009.

ATTALI, Jacques. Karl Marx ouL'esprit du monde. Paris, Fayard, 2005.

FREUD, Sigmund. O mal-estar na cultura. Porto Alegre, LP/M, 2011.

ILYENKOV, Evald. Dialectics of the abstract and the concrete in Marx,s Capital. Moscou, ProgressPublishers, 1982.

KOSIK, Karel. Dialética do concreto. Rio de Janeiro, Paz e Terra, 1976.

LEFREBVRE, Henri. Marxismo. Porto Alegre, LPM, 2011.

MATTHEWS, Eric. CompreenderMerleau-Ponty. Petrópolis, Vozes, 2010.

MERLEAU-PONTY, Maurice. As aventuras da dialética. São Paulo, Martins Fontes, 2006.

MERLEAU-PONTY, Maurice. O visível e o invisível. São Paulo, Perspectiva, 2012.

SARTRE, Jean-Paul. Critique de laraisondialectique. Paris, Gallimard, 1985.

\begin{tabular}{|c|c|c|c|c|}
\hline Genista Oialeotus & Ano 2 & n. 6 & Janeiro - Agosto 2015 & p. $177-191$ \\
\hline
\end{tabular}

